\title{
Intersecções entre escrita e imagem em $A$ coleção particular, de Georges Perec
}

\author{
Sabrina Ferraz Fraccari ${ }^{\mathrm{i}}$
}

\begin{abstract}
RESUMO
O artigo tem como objetivo estudar as relações que se estabelecem entre literatura/escrita e pintura/imagem na novela A coleção particular, do escritor francês Georges Perec, de modo a perceber e analisar as intersecções entre elas ao longo da narrativa. A fim de compor seu labirinto, Perec retoma a polêmica do Ut pictura poesis ("Um poema é como um quadro") e as disputas entre pintura e literatura no interior do campo artístico, buscando refletir sobre o jogo de poder nesse cenário. Neste sentido, literatura/escrita e pintura/imagem são, na novela de Perec, potencialidades que jogam juntas e se complementam mutuamente, oferecendo mais caminhos ao leitor.
\end{abstract}

Palavras-chave: Ut pictura poesis; Campo artístico; Literatura; Pintura; Poéticas interartes.

\section{RESUMEN}

El artículo objetiva estudiar las relaciones establecidas entre literatura/escrita y pintura/imagen en la novela Un cabinet d'amateur, del escritor francés Georges Perec, para comprender y analizar las intersecciones entre ellas a lo largo de la narrativa. A fin de componer su laberinto, Perec retoma la polémica del Ut pictura poesis ("Un poema es como un cuadro") y las disputas en el interior del campo artístico entre pintura y literatura para reflejar acerca del juego de poder en este escenario. Así, literatura/escrita y pintura/imagen son, en la novela de Perec, potencialidades que juegan juntas y se complementan una al otra, ofreciendo más caminos al lector.

Palabras clave: Ut pictura poesis; Campo artístico; Literatura; Pintura; Poéticas interartes.

\section{CONSIDERAÇÕES INICIAIS}

\footnotetext{
${ }^{\mathrm{i}}$ Graduada em Letras - Português e Espanhol pela Universidade Federal da Fronteira Sul (UFFS), campus Cerro Largo/RS. Mestranda em Estudos Literários na Universidade Federal de Santa Catarina (UFSM). ORCID: https://orcid.orh/0000-0001-6656-9417 | sabrina.fraccari@acad.ufsm.br

O presente trabalho foi realizado com apoio da Coordenação de Aperfeiçoamento de Pessoal de Nível Superior - Brasil (CAPES) - Código de Financiamento 001.
} 
A novela A coleção particular (Un cabinet d'amateur), do escritor francês Georges Perec, publicada em 1979, é um texto labirinto que nos oferece uma infinidade de possibilidades - não necessariamente independentes umas das outras -, a depender do que, enquanto leitores, estivermos buscando. O narrador nos conduz através das manifestações culturais organizadas pela comunidade alemã da cidade americana de Pittsburgh, Pensilvânia, a fim de comemorar o $25^{\circ}$ aniversário do reinado do imperador Guilherme II. Uma dessas manifestações foi a exposição de pintura realizada nos salões do Hotel Bavária, de abril a outubro, que alcançou grande sucesso em virtude, especialmente, do quadro “A coleção particular”, de autoria de Heinrich Kürz, pintor americano de origem alemã.

Arbex (2002, p. 79) aponta alguns dos labirintos construídos por Perec na novela em questão, tais como “a multiplicação do 'eu', a enquete sobre a identidade e o desaparecimento, os jogos intertextuais, a reflexão sobre o espaço como lugar de reunião e de dispersão, ilustrada plenamente pela imagem do quebra-cabeças". Além disso, a pesquisadora ressalta o fato de a narrativa ter como tema uma pintura o que, segundo ela, permite que se pense "a pintura em sua relação com a escritura" (ARBEX, 2002, p. 80). E proporciona, ainda, a reflexão acerca das fronteiras entre realidade e ficção, por ter sido a pintura "fundada tradicionalmente sobre a mimese, sobre uma concepção da representação como reprodução (fiel, se possível) do real" (ARBEX, 2002, p. 80).

Uma vez que a novela de Perec trata sobre uma pintura, o nosso objetivo no presente artigo consiste em estudar as relações que se estabelecem entre literatura/escrita e pintura/imagem, de modo a perceber e analisar as intersecções entre elas ao longo da narrativa. Para compor os labirintos, Perec retoma a polêmica do Ut pictura poesis ("Um poema é como um quadro") e as disputas entre pintura e literatura no interior do campo artístico, buscando refletir sobre o jogo de poder nesse cenário. Tal polêmica reencena a discussão entre a especificidade das artes, uma vez que, conforme lembra Moser (2006), a tradição ocidental costuma perceber as artes como distintas. Além disso, é importante ressaltar a importância das imagens para a literatura perequiana, pois o autor abusa das descrições em seus textos, valendo-se da plasticidade da língua escrita e investindo na criação de imagens por meio da palavra (SILVA, 2015). 
Contudo, para além de acrescentar elementos à discussão sobre o campo artístico, o texto do escritor francês rompe com o pacto ficcional firmado com o leitor, e aponta a si mesmo enquanto ficção. Perec, lembremos, fez parte do grupo francês OuLiPo (Ouvroir de Littérature Potentielle - Laboratório de Literatura Potencial), formado nos anos 1960, que buscava experimentar "novas 'estruturas' de natureza matemática ou novos procedimentos que contribuíssem com a atividade literária" (PINO, 2004, p. 50), questionando, desta forma, o automatismo e a suposta inspiração do escritor no processo de composição do texto literário.

A coleção particular pode também ser considerada um künstlerroman, ou romance de artista, "narrativa na qual o personagem de um artista ou uma obra de arte real ou fictícia exercem uma função estrutural essencial” (ARBEX, 2002, p. 80). O romance de artista é um gênero popularizado no século XIX, com textos como A obraprima ignorada (Le Chef-d'oeuvre inconnu), conto de Balzac, escrito em 1831. Lago (2017, p. 26) afirma que o künstlerroman é "uma forma literária que privilegia o encontro entre as artes" e, portanto, possibilita discussões acerca das interações entre as diferentes artes. A novela de Perec, embora não ponha o artista - no caso, o pintor Kürz - como protagonista, desloca a pintura - o quadro "A coleção particular" - ao centro do debate, e permite que nos interroguemos a respeito da relação entre pintura e literatura.

A coleção particular é um texto abarrotado de imagens. As descrições de quadros se multiplicam no interior da obra, sendo tanto apresentadas pelo narrador como por outros escritores, que tomam a palavra de modo a estabelecer a autonomia e relevância do quadro pintado por Kürz junto ao campo artístico. Em um primeiro momento, é possível afirmar que as discussões sobre a submissão da pintura à literatura (escrita), a polêmica do Ut pictura poesis, que remontam aos diálogos platônicos, porém especialmente ao Renascimento, encontram no texto de Perec uma nova roupagem, na qual a escrita está a serviço da pintura. No entanto, em A coleção particular encontramos mais do que isso: literatura e pintura, palavra e imagem, não são valores opostos, que competem entre si para ver quem alcança o domínio do campo artístico, mas duas potencialidades que jogam juntas e se complementam mutuamente.

\section{O CAMPO ARTÍSTICO E O JOGO DE PODER}


O quadro "A coleção particular" foi encomendado a Kürz pelo empresário Hermann Raffke, dono das cervejarias Raffke, e também da coleção de obras exposta no Hotel Bavária. O jornal Vaterland publicou um artigo sobre a exposição, escrito por Thadeus Doppelgleisner, no qual o colecionador é apresentado como "um esclarecido e dinâmico amante das artes, bem conhecido das mostras e ateliês de ambos os lados do Oceano" (PEREC, 2004, p. 13). A coleção, reunida por Raffke "com um discernimento eclético e seguro" (PEREC, 2004, p. 13), contou também com a ajuda de peritos em arte e continha um conjunto significativo de pinturas tanto antigas quanto modernas sem parâmetros nos Estados Unidos, capaz inclusive, de causar inveja a museus europeus.

Essa magnífica coleção estava exposta nas festividades organizadas pela comunidade alemã, junto ao quadro "A coleção particular". Os jornais de Pittsburgh dedicaram pequenas notas sobre os quadros nas seções destinadas à crítica de arte, com comentários genéricos, entretanto, enfatizando apenas alguns nomes de artistas e títulos de obras. Já o quadro pintado por Kürz foi recebido com mais entusiasmo, e motivou notas elogiosas, embora curtas, além do artigo publicado no jornal Vaterland, um dos responsáveis por organizar as festividades. $\mathrm{O}$ narrador atribui a extensão do artigo do Vaterland ao fato de Raffke ter sido um dos patrocinadores do evento:

\footnotetext{
O artigo do Vaterland, cujo autor, Thadeus Doppelgleisner, era um dos responsáveis pela exposição, foi nitidamente mais desenvolvido (talvez porque o proprietário do quadro Hermann Raffke, das cervejarias Raffke, houvesse emprestado várias obras e generosamente financiado a exposição) [...] (PEREC, 2004, p. 13).
}

A explicação que o narrador nos apresenta acerca da construção da exposição bem como de seu sucesso, especialmente aquele alcançado pelo quadro de Kürz, permite perceber alguns pontos sobre os quais está estabelecido o que Bourdieu (1996) chama de campo artístico. A medida em que tal campo se autonomiza dos poderes econômicos e políticos, passa a constituir um espaço no qual certas lógicas econômicas são invertidas, e diferentes atores e instituições competem entre si para alcançar a autoridade do campo. O campo artístico afirma-se, sobretudo, a partir de critérios opostos às normas da Academia, que tutelou os pintores durante muito tempo, mas também contra o caráter comercial lucrativo das obras de arte. Estas, por sua vez, são consideradas bens simbólicos, que "somente se tornam obras de arte, quando reconhecidos como tal - por 
instâncias de seleção e de legitimação competentes” (JURT, 2005, p. 87), instaurando, assim, os outros atores do campo.

Conforme o campo artístico rompe com o utilitarismo burguês, a figura do artista adquire um lugar de exceção, gozando então de um status que o coloca fora das disputas empreendidas no campo de poder. A posição de artista garante ao indivíduo a fuga ao mundo burguês, e assegura seu caráter desinteressado de quem busca apenas a glória através da criação de obras de arte. Tal status, por exemplo, permitiu a saída de Kürz da cena, sem exigir maiores questionamentos, o que contribuiu para que a farsa elaborada por Raffke fosse mantida até o fim da narrativa.

No entanto, o caráter de exceção garantido ao artista, responsável por posicionálo em oposição ao burguês e garantir-lhe certos privilégios, acaba por incomodar os próprios burgueses que, mesmo possuindo condições financeiras, não alcançam o prestígio do artista, conforme análise feita por Bourdieu (1996). Hermann Raffke se apresenta como esse burguês em busca da distinção e admiração garantidas ao artista, alcançadas graças à posição de mecenas que ocupa, haja vista os inúmeros elogios que recebe nos jornais da cidade, especialmente do Vaterland. A aproximação ao artista garante também o afastamento de Raffke dos outros atores do campo, os conhecidos peritos em arte e marchands, que o enganaram e que serão enganados por ele como forma de vingança.

Para que a desforra do colecionador fosse completa, o quadro pintado por Kürz justamente aquele que retrata a coleção particular de Raffke dando mostras do poder alcançado pelo empresário - teria de alcançar certa autonomia e importância junto ao campo artístico. Neste ponto, entra em cena a polêmica do Ut pictura poesis que merece um pouco mais de atenção. Jacqueline Lichtenstein (2005), no texto O paralelo das artes, retoma a doutrina do Ut pictura poesis e a oposição que esta promove entre poesia e pintura, resultando em uma comparação entre as duas artes: "Ut pictura poesis" - "um poema é como um quadro".

As reflexões comparativas entre pintura e literatura (escrita e imagem) remontam à Antiguidade Clássica e foram transmitidas a nós por Horácio, em sua Epístola aos Pisãos, datada do século I. Por meio da oposição entre as artes dirigidas ao ouvido e aquelas dirigidas aos olhos, que tomou a forma da doutrina conhecida como Ut pictura poesis, Horácio institui a comparação entre poesia e pintura, e marca a pintura como 
modelo da poesia. Assim, é estabelecida uma relação de dominação entre as duas artes, "o que prepara a cena para a libertação ou, pelo menos, a emancipação de uma arte em relação à outra" (MOSER, 2006, p. 44). Neste sentido, o campo artístico se torna um espaço de interações múltiplas, que podem acabar tornando-se conflituosas e revelar uma disputa de poder no interior deste campo.

Quando, no Renascimento tal afirmação foi retomada, inverteu-se o sentido dado por Horácio, e estabeleceu-se a pintura como termo de referência: "Ut poesis pictura", ou “a pintura é como a poesia”. Essa inversão se deve, de acordo com Lichtenstein (2005), sobretudo à necessidade de responder às novas exigências surgidas no campo das artes e que se relacionam à transformação da situação dos pintores e da pintura. A doutrina do Ut pictura poesis foi um dos meios que permitiu à arte pictural alcançar o reconhecimento antes reservado apenas às artes da linguagem. Remontando a Platão, que via a pintura como cópia da cópia, ou uma prática ilusória, e à Idade Média, que colocava a pintura como uma arte "mecânica", o Ut pictura poesis buscou legitimar social e teoricamente a pintura, tentando provar ser ela também proveniente da ideia, do intelecto e da teoria. Tal legitimidade, no entanto, só poderia ser alcançada aproximando a pintura da linguagem, que representa, desde a Antiguidade, a ordem do discurso e da razão.

No entanto, ao tentar legitimar a pintura, o Ut pictura poesis acabou por imporlhe as categorias da poética e da retórica e, conforme Lichtenstein (2005), ao mesmo tempo em que reconheceu literatura e pintura como irmãs, acabou por reafirmar-lhes como rivais. Isso porque, ao mesmo tempo "que lhe assegura uma dignidade, a comparação com a poesia impõe à pintura uma definição que oculta sua especificidade, já que a submete às artes da linguagem" (LICHTENSTEIN, 2005, p. 13). Assim, a doutrina do Ut pictura poesis acaba por reafirmar uma disputa entre literatura e pintura, "cujo ponto central era o da superioridade da linguagem ou da imagem" (LICHTENSTEIN, 2005, p. 14). Dessa forma, ao mesmo tempo em que assegurou à pintura certa dignidade, o Ut pictura poesis impôs a ela uma definição com base nas artes da linguagem, ocultando suas especificidades. Assim, na narrativa de Perec, para que a pintura de Kürz fosse alçada ao status de obra de arte, seria necessário que os textos escritos atestassem sua relevância.

Tanto os jornais, por meio das seções destinadas à crítica de arte, quanto a longa nota que descreve minuciosamente o quadro de Kürz contribuíram para a pintura alcançar 
sucesso junto ao público, que reagiu entusiasmado e desafiado pelo que viu. Além disso, Raffke contou com os estudos acadêmicos de Lester Nowak, ressaltando a singularidade do quadro "A coleção particular", sobretudo em virtude da reprodução do mesmo quadro no quadro (mise en abyme), que Kürz acrescentou. Nowak fornece uma interpretação para tal detalhe, sugerindo que ele representaria a impossibilidade de o artista criar algo realmente novo, pois “um número considerável de quadros, se não todos, só assumem seu verdadeiro significado em função de obras anteriores" (PEREC, 2004, p. 22). Nowak também empreende em seu estudo uma análise minuciosa por meio da qual objetiva provar que a obra de Kürz "era em si mesma uma verdadeira 'história da pintura"” (PEREC, 2004, p. 23), assinalando sua singularidade na história das artes dirigidas aos olhos.

Dessa forma, a fim de validar a pintura "A coleção particular" junto ao campo artístico, Raffke procede de modo a reconstituir esse campo como um meio de alcançar sua vingança. Ao fazer isso, acaba por questionar o próprio campo, cujos atores, tradicionalmente apresentados como peritos em arte, acabaram sendo facilmente enganados por um falsário. Por fim, Raffke também recompõe a polêmica do Ut pictura poesis e a separação entre pintura e literatura, na qual a primeira precisa da validação por meio do escrito, porém o faz de modo contrário: a relevância de tais textos se dá em um contexto no qual a pintura é a protagonista, e não há se não uma disputa por espaço dentro da história mesma da própria arte pictural. Os textos escritos, dessa forma, buscam legitimar a pintura de Kürz junto ao campo artístico, seja por meio de estudos acadêmicos, seja através da atuação da imprensa. No entanto, a narrativa de Perec, ao apontar a si mesma como pastiche, ilusão, fingimento, rompendo o pacto ficcional, permite que voltemos nossos olhos não só ao que o texto em si projeta, mas também àquilo que está fora dele, mas nele se reflete.

\section{REAPROXIMAÇÕS ENTRE PINTURA E LITERATURA}

Colocadas em lados opostos, pintura e literatura acabaram se reencontrando sobretudo a partir do século XIX, no contexto francês, quando, segundo Jurt (2005), a pintura se desprendeu da tutela da Academia e passou a postular sua independência. $O$ rompimento com a Academia proporcionou um novo sistema de consagração e difusão 
das obras de arte, o chamado sistema "marchand-crítico", que concedeu grande relevância à figura do crítico de arte, um dos responsáveis por produzir o valor social da obra. Jurt (2005) nos lembra que os "bens simbólicos”, na perspectiva de Bourdieu, somente podem ser reconhecidos como obra de arte quando legitimados por instâncias de seleção competentes, como pontuamos anteriormente. Tais instâncias envolvem uma série de atores, entre eles o crítico de arte, função exercida por diversos escritores, que praticavam a chamada crítica de arte "literária". Este tipo de crítica representa, segundo Jurt (2005), um ponto de intersecção entre o campo literário e o campo artístico.

Jurt (2005), a partir das observações de Dario Gamboni, apresenta outros pontos de aproximação entre literatura e pintura no contexto francês do final do século XIX, tais como similaridades nas formas de expressão e afinidades temáticas. No entanto, embora apresentando pontos de intersecção, a literatura ainda servia de instância legitimadora à pintura, e essa marca de superioridade responsável por separar as duas artes, se daria ainda em função do fato de os escritores críticos de arte se expressarem a partir do texto escrito, modalidade que dominam. A escrita, empreendida como o espaço da razão, do ordenamento racional das ideias, precisaria retomar (ou reconhecer) uma dimensão imagética a fim de reestabelecer os laços mais arraigados entre escrita e imagem, literatura e pintura. É aqui que Mallarmé lança os seus dados.

A separação entre pintura e literatura, ademais de caracterizar uma disputa pelo monopólio de poder no campo artístico, se dá também em função da antiga separação entre escrita e imagem. Segundo Arbex (2006, p. 19), com a publicação de Un coup de dés n'abolira jamais le hasard, em 1897, "Mallarmé reintegrou ao alfabeto seu elemento visual e espacial" e, então, "a cultura alfabética foi tomada pela imagem”. A reintegração do visual à escrita é postulada por Arbex com base na tese de Anne-Marie Christin (2006), segundo a qual a escrita nasceu da imagem. Tal afirmação põe a imagem como anterior à escrita e se contrapõe à noção de que esta é mero recurso para transcrever o discurso oral, sendo tomada como uma espécie de duplo da linguagem oral. Christin (2006), por sua vez, defende que a escrita torna a palavra visível, e não somente reproduz uma sequência de sons. Mais do que privilegiar um ou outro aspecto, a autora pretende estabelecer o caráter dúplice da palavra, apoiada tanto sobre o registro verbal quanto sobre o gráfico.

O caráter misto da palavra, nos termos de Christin (2006), permite considerar, ademais das figuras, o suporte, o que nos leva à noção de superfície, da redescoberta do 
espaço, a página enquanto tela, a letra enquanto imagem. São essas as bases da poética de Mallarmé, que constrói imagens com palavras e redescobre o vazio, o silêncio das margens e do espaçamento do texto. Os espaços em branco na página adquirem significado, como quando o narrador de A coleção particular opta por apresentar informações sobre os quadros vendidos no segundo leilão da coleção de Raffke, tais como o preço de venda de cada um, a escola a qual pertencem e breves descrições picturais de alguns. Ao fazer isso, são criados espaços em branco no texto, que servem como delimitação a cada quadro, preenchendo a página com retângulos. Estes, conforme distanciamos o olhar, lembram o formato mesmo dos quadros reproduzidos pela pintura de Kürz na parede atrás de Raffke.

Dessa forma, é importante lembrar as considerações de Lessing, em seu tratado Laocoonte, publicado em 1766, na qual são estabelecidas algumas distinções entre poesia e pintura. Entre as principais estão a restrição da poesia enquanto arte do tempo na qual deve ser representada uma sequência de ações, enquanto a pintura seria uma arte do espaço, e representa, portanto, a simultaneidade de um instante apenas (MOSER, 2016). Para além destas, Moser (2016) destaca a questão da materialidade das duas artes, que seria determinante também para marcar as diferenças. Segundo o pesquisador, Lessing propõe a todas as artes uma midialidade específica, e ela é responsável por suas possibilidades de representação:

\begin{abstract}
Ele [Lessing] teria, assim, legislado ao estabelecer fronteiras claras e nítidas entre duas categorias diferentes - tudo isso com base nas condições e possibilidades midiáticas das duas artes em questão. O que Lessing "descobre" não é inteiramente novo; o que é novo é o fato de chamar atenção sobre esse ponto, bem como seu gesto legislador. Ele teria criado categorias conceituais que funcionam segundo a lógica da não-contradição: isso não é aquilo, isso não pode ao mesmo tempo ser aquilo. Em virtude de suas condições midiáticas, a poesia (que representa o desenrolar de uma ação enquanto sucessão temporal dentro de uma mídia que é, por sua vez, de natureza transitória) não pode fazer a mesma coisa que a pintura (representar um ou vários corpos dentro de um todo espacial percebível dentro de uma simultaneidade temporal) e vice-versa (MOSER, 2016, p. 45).
\end{abstract}

Neste sentido, quando o narrador de A coleção particular nos oferece informações detalhadas a respeito dos quadros expostos, e as organiza de modo a compor pequenos retângulos, estaria fazendo uso de um recurso (a espacialidade) próprio à pintura e, portanto, jogando com as zonas cinzentas sob as cais recaem qualquer tentativa de delimitação entre as artes. Contudo, mais do que tecer recortes na página a fim de lembrar 
recortes dos quadros, este narrador faz uso constante das descrições picturais, que acabam por reproduzir as pinturas na imaginação do leitor.

As descrições picturais, segundo Louvel (2012), representam os graus de saturação do texto pelo pictural, sendo a écfrase o grau de maior saturação pictural possível de ser alcançado pelo texto. Exercício literário que visava descrever uma obra de arte, Louvel (2012, p. 60) atualiza a écfrase, apresentando-a como síntese a partir da qual "a poesia faz [...] falar a obra de arte". A écfrase, então, seria o momento do texto quando alguma personagem ou narrador se põe a descrever um determinado cenário ou paisagem ou, como ocorre na narrativa de Perec, pinturas.

A primeira descrição pictural do quadro "A coleção particular" foi feita na nota anônima que compôs o catálogo da exposição, uma das responsáveis pelo sucesso do quadro, segundo o narrador. Da perspectiva do leitor bem como dos espectadores personagens, a écfrase presente na nota constrói o quadro em nossa imaginação. A descrição nos apresenta o colecionador Raffke sentado em seu gabinete diante dos mais de cem quadros colocados ao fundo, que compõem sua coleção particular. O autor da nota se furta a descrever todos esses quadros, porém afirma que ali estão presentes representantes de

\footnotetext{
todos os gêneros e todas as escolas de arte da Europa e da jovem pintura americana estão aí admiravelmente representados, os temas religiosos bem como as cenas de gênero, tanto os retratos como as naturezas-mortas, paisagens, marinhas etc, deixando aos visitantes o prazer de descobrir, de reconhecer, de identificar o Longhi ou o Delacroix, o Della Notte ou o Vernet, o Holbein ou o Mattei e outras obras-primas, dignas dos mais importantes museus da Europa, que o amador Raffke, inteligentemente aconselhado por eminentes peritos, conseguiu descobrir em suas viagens (PEREC, 2004, p. 15).
}

Os quadros que compõem a coleção de Raffke, dessa forma, também representados na pintura feita por Kürz acabam por reconstituir a história da pintura, ou pelo menos partes dela. As três pinturas que o autor da nota se põe a descrever (uma "Visitação", "Os preparativos do almoço", uma natureza-morta de Chardin, e o "Retrato de Bronco McGinnis", de Adolphus Kleidorst), representam três temas importantes na história da pintura: os temas religiosos, a natureza-morta e o retrato. Assim, conforme os observadores de "A coleção particular" alcançarem identificar os quadros originais reproduzidos na pintura, poderão reconstituir, a partir dela, o percurso histórico dessa arte. 
Além disso, a descrição pictural do quadro de Kürz revela a presença da mise en abyme, pois o pintor acabou por inserir o próprio quadro ao centro da pintura, caracterizando o que o autor da nota anônima chamou de "surpresa maravilhosa" (PEREC, 2004, p. 18). Mise en abyme, cabe ressaltar, foi uma noção operacionalizada por André Gide em seus diários. Ele, porém, não cunha o termo, tampouco propõe uma definição específica. Neste sentido, para Claro (2017), o escritor francês interessa-se por obras que "contêm dentro de si uma espécie de duplicação especular que repete ou reflete parte ou a totalidade da obra englobante", e é a partir daí que a mise en abyme começa a ser pensada.

Foi Dällenbach (1991, p. 16), contudo, quem ofereceu uma definição inicial para o conceito: "es mise en abyme todo enclave que guarde relación de similitud con la obra que lo contiene". Antes, porém, de propor tal definição, o pesquisador estabeleceu quatro pontos para servirem de referência quando tratarmos deste tema, são eles: a mise en abyme é o órgão pelo qual a obra se volta sobre si mesma e, portanto, se manifesta como modalidade de reflexo; ela ressalta, essencialmente, a inteligibilidade e estrutura formal da obra; constitui uma realidade estrutural que não é exclusiva da literatura em si; e, por fim, marca Gide como aquele que descobriu tal procedimento (DÄLLENBACH, 1991).

Não nos alongaremos em questões teóricas, visto que nosso interesse recai sobre os efeitos causados pela presença deste recurso na novela de Perec. A mise en abyme pode ser identificada no quadro de Kürz, onde, a cada redução feita, o pintor acrescentou um detalhe diferente, que passou a ser encontrado pelos observadores mais atentos:

\footnotetext{
Mas não se custou a perceber que, ao contrário, ele se obrigara a jamais copiar estritamente seus modelos e parecia encontrar um prazer maligno em introduzir sempre uma minúscula variação; de uma cópia a outra, personagens, detalhes desapareciam ou mudavam de lugar ou eram substituídos por outros; o bule de chá do quadro de Garten tornava-se uma cafeteira de esmalte azul; um lutador de boxe, ainda vigoroso na primeira cópia, recebia um terrível uppercut na segunda e tombava na lona na terceira; máscaras de carnaval (Uma festa no Palácio Quarli, de Longhi) enchiam uma piazetta a princípio deserta [...]" (PEREC, 2004, p. 20).
}

Cada redução, ademais de representar os mesmos quadros, sofria o acréscimo de um detalhe que, em virtude da mise en abyme, acabou por compor também pequenas narrativas. Um lutador de boxe perde a luta, personagens se modificam aos poucos, redução após redução, um pastor perde progressivamente suas ovelhas, personagens 
mudam de forma representando a passagem do tempo. Assim, a partir da reflexividade na qual a obra é mergulhada, cada redução feita do quadro contém também uma narrativa que se modifica na redução seguinte, e encena, desta forma, a dinâmica da passagem do tempo, tornando este um elemento também constituinte da pintura. Lembremos novamente Lessing, pois um dos critérios usados por ele a fim de marcar as fronteiras entre poesia e pintura foi o da especificidade das artes, ligando a pintura ao espaço e a poesia ao tempo. Assim, ao introduzir a mise en abyme no quadro "A coleção particular", o pintor rompe com uma das bases a definir a especificidade das artes, situação que reforça as intersecções entre escrita/literatura e imagem/pintura ao longo da narrativa de Perec.

Neste sentido, ao mesmo tempo em que o narrador retoma a polêmica do $U t$ pictura poesis e reencena, portanto, o jogo de poder no interior do campo artístico, pautado pela especificidade das artes, perturba este argumento ao fazer uso da mise en abyme, pois a partir dela, literatura/escrita e pintura/imagem, compartilham, na narrativa, características comuns. Assim, conforme o leitor alcança reconhecer, no texto, os elementos do campo artístico que legitimam o quadro "A coleção particular", tais como o uso de textos escritos a fim de estabelecer a sua relevância, a presença do colecionador e os marchands, percebe que esta discussão abre espaço a outra, encenada no próprio quadro. Esta, por sua vez, opera no sentido de superar a especificidade das artes e, portanto, questionar as fronteiras entre literatura/escrita e pintura/imagem.

A dinâmica proposta pela novela de Perec, de estabelecer uma discussão para, em seguida, propor outra a partir dela, revela um jogo estético próprio ao OuLiPo. Tal jogo encaminha-se para um outro nível quando o narrador, ao final do texto, adverte o leitor a respeito não apenas da falsificação dos quadros do colecionador Raffke, como do próprio texto ficcional: "verificações conduzidas com diligência não custaram a demonstrar que, de fato, a maior parte dos quadros da coleção de Raffke eram falsos, como são falsos a maioria dos detalhes desta narrativa, concebida unicamente pelo prazer, pelo gosto de iludir" (PEREC, 2004, p. 72). Desta forma, a narrativa rompe abruptamente o pacto firmado com o leitor ao apontar a si mesmo como ficção, expulsando-o de um dos labirintos possíveis.

\section{O LEITOR É EXPULSO DE UM LABIRINTO}


Alguns anos após o leilão da coleção de Raffke, aqueles que adquiriram as obras receberam uma carta assinada por Humbert Raffke, sobrinho do colecionador, e o falsário responsável pelas reproduções. A motivação de Raffke para armar todo o esquema de falsificação, que envolveu também outros como Nowak, foi o fato de ter sido ele também enganado quando comprou seus primeiros quadros. Por isso, resolveu vingar-se, organizando "a operação que lhe permitiria, anos mais tarde e mesmo após sua morte, mistificar por sua vez os colecionadores, os peritos e os marchands" (PEREC, 2004, p. 72). Dessa forma, ao reproduzir o sistema de validação do campo artístico para legitimar obras de arte falsas, meras cópias, Raffke contribui para questionar a validade e autonomia do próprio campo.

De outra parte, a presença da mise en abyme mergulha a obra num jogo de reflexos infinito que reproduz a multiplicidade própria à modernidade. Esta, na perspectiva de Compagnon (1996b), tem como tradição a constante ruptura, e, portanto, constitui um impasse lógico, pois volta-se contra si mesma e, na medida em que afirma a arte, também a nega, decretando sua morte. A tradição moderna seria então uma aliança dos contrários a revelar o moderno como uma tradição da negação, na medida em que institui e reconhece o novo como valor a ser alcançado pela arte. Neste sentido, tal tradição propõe um jogo com o leitor/espectador, pois precisa do público para renovar a si mesma (COMPAGNON, 1996b). Assim, quanto mais estranhamento as obras consideradas modernas causarem sobre o leitor/espectador, mais longe levam a tradição da ruptura.

Para além do jogo proposto pela tradição moderna, Perec, como escritor integrante do movimento OuLiPo, acrescenta outros elementos ao jogo com o leitor. Peça fundamental para o OuLiPo, Pino (2004) afirma que cabe a ele [leitor] se movimentar entre os caminhos do labirinto, encontrando as melhores passagens e demonstrando presença ativa frente ao texto literário. Silva e Sanchotene (2021) lembram ainda que, em certa medida, o leitor acaba sendo tomado como um adversário pelo escritor oulipiano, que compõe o texto labirinto com várias saídas, ou várias peças de um quebra-cabeça, e exige do leitor a decisão sobre por qual caminho seguir ou qual peça encaixar. A vida modo de usar, romance de Perec publicado em 1978, por exemplo, exige que o leitor separe as peças oferecidas pelo escritor e monte, ele próprio, a narrativa a fim de conferir a ela algum sentido. 
Em A coleção particular, Perec convida o leitor a aventurar-se pelos caminhos possíveis dos labirintos que constrói, e oferece, em um primeiro momento, a discussão a respeito de uma possível primazia de uma arte sobre as outras ao reencenar a polêmica do Ut pictura poesis, reforçando, com isso, a especificidade das artes. Contudo, a discussão não se restringe a esta polêmica, pois, por meio da mise en abyme presente no quadro pintado por Kurz, as dimensões escritas e imagéticas se misturam, e as pretensas fronteiras entre as artes acabam sendo rompidas.

Se, como afirma Nowak, "toda obra é um espelho de uma outra" (PEREC, 2004, p. 22), também todo texto literário é um labirinto, conforme Compagnon (1996a, p. 44), "uma rede de citações em ação", pois, ao mesmo tempo em que o autor escreve seu próprio texto, produz também a citação a outros textos. Expulso o leitor de um dos labirintos por meio da suspensão do pacto ficcional operada conscientemente pelo narrador, ele se junta aos compradores dos quadros de Raffke: apenas se dá conta de que está diante de uma farsa quando é advertido a respeito dela, e precisa se reorientar pelos caminhos que o texto oferece.

\section{CONSIDERAÇÕES FINAIS}

Os labirintos de A coleção particular são compostos por diferentes caminhos. No presente artigo, optamos por nos deter nas intersecções entre pintura/imagem e literatura/escrita, pois a novela de Perec põe em cena a coleção de telas de Hermann Raffke, um apreciador da arte pictural. Entre os quadros que compõem tal coleção está “A coleção particular”, pintado por Heinrich Kürz e o responsável por grande parte do sucesso alcançado pela exposição de pintura realizada no Hotel Bavária. Para que a obra de Kürz alcançasse prestígio junto ao campo artístico, Raffke recorre ao estudo de Lester Nowak e às notas críticas publicadas nos jornais da cidade. Desta forma, é recuperada a polêmica do Ut pictura poesis e as disputas entre literatura/escrita e pintura/imagem pelo monopólio de poder no interior do campo artístico.

Na novela de Perec, porém, os textos escritos estão a serviço da pintura, pois a farsa proposta por Raffke põe a pintura ao centro da discussão. Contudo, ademais de inverter os papeis tradicionais ocupados por literatura e pintura no jogo de poder encenado no interior do campo artístico, o texto do escritor francês nos oferece uma nova 
perspectiva de análise ao saturar o texto com descrições picturais, e redescobre as funcionalidades da página, usando-a também como tela. Neste sentido, com base em Christin (2006), entendemos a escrita não apenas como um duplo do discurso oral, mas como um meio de tornar a palavra visível e aproximá-la, portanto, da imagem. Quando o narrador de A coleção particular se propõe a descrever as telas que fazem parte da coleção de Raffke, está acenando para o leitor, solicitando que reconstrua tais imagens a partir da palavra.

Entretanto, todos os quadros são falsos, bem como a própria narrativa, e o narrador pode rir do leitor, assim como Raffke riu dos ditos peritos em arte, incapazes de identificar as telas inautênticas. Perec, ao modo oulipiano, convida o leitor para o seu labirinto, e lhe oferece diversos caminhos que conduzem a outros labirintos. Enquanto o leitor caminha pela exposição de quadros falsos que são respaldados pela academia e pela imprensa, reencenando uma separação entre as artes, a narrativa caminha de modo a superar este debate ao revelar intersecções entre escrita e imagem.

Ao final da narrativa, porém, o narrador revela que também a novela $A$ coleção particular, assim como os quadros da coleção de Raffke, é uma farsa, produzida somente “pelo prazer, pelo gosto de iludir" (PEREC, 2004, p. 72). Afinal, o importante para o OuLiPo é o jogo, e a cada vez que o texto nos oferece mais possibilidades de leitura, seguimos por elas encontrando novos labirintos que desembocam em discussões aparentemente superadas que, no entanto, retornam ao centro do debate. Não nos cabe, portanto, esgotar as análises, mas apenas sugerir outros possíveis caminhos de interpretação.

\section{Referências}

ARBEX, Márcia. Jogos especulares em Un Cabinet d'amateur, história de um museu particular. Revista Alea, Rio de Janeiro, v. 04, n 01, pp. 79-89, 2002.

. "Poéticas do visível: uma breve introdução". In:

(Org.) Poéticas do visível. Ensaios sobre a escrita e a imagem. Belo Horizonte: PósLit/FALE/UFMG, 2006, pp. 17-62.

BOURDIEU, Pierre. As regras da arte: gênese e estrutura do campo literário. Tradução de Maria Lúcia Machado. São Paulo: Companhia das Letras, 1996. 
CHRISTIN, Anne-Marie. "A imagem enformada pela escrita". In: ARBEX, Márcia (Org.) Poéticas do visível. Ensaios sobre a escrita e a imagem. Belo Horizonte: PósLit/FALE/UFMG, 2006, pp. 63-106.

CLARO, Alexandre E. M. A. dos Santos. O vórtice abissal: a mise en abyme e o filme estrutural. 2017. 155f. Dissertação (Mestrado em Arte Multimédia) - Faculdade de BelasArtes, Universidade de Lisboa. Lisboa, 2017.

COMPAGNON, Antoine. O trabalho da citação. Tradução de Cleonice Mourão. Belo Horizonte: Editora UFMG, 1996a.

"Tradição moderna, traição moderna". In: Os cinco paradoxos da modernidade. Tradução de Cleonice Mourão, Consuelo Santiago e Eunice Gálery. Belo Horizonte: Editora UFMG, 1996b, pp. 9-14.

DÄLLENBACH, Lucien. El relato especular. Tradução de Ramón Buenaventura. Madrid: Visor, 1991.

JURT, Joseph. Champ littéraire et champ artistique en France (1880-1900). Revista Terceira Margem, v. 9, n. 13, pp. 82-102, 2005.

LAGO, Izabela Baptista do. Do künstlerroman às narrativas de artista: um estudo conceitual. 2017. 193f. Dissertação (Mestrado em Letras) - Faculdade de Letras, Universidade Federal de Minas Gerais. Belo Horizonte, 2017.

LICHTENSTEIN, Jacqueline. "O paralelo das artes". In: (Org.) A pintura. Textos essenciais. O paralelo das artes. São Paulo: Editora 34, 2005, pp. 9-27.

LOUVEL, Liliane. "Nuanças do pictural". In: DINIZ, Thais F. N. (Org.) Intermidialidade e estudos interartes. Desafios da arte contemporânea. Belo Horizonte: Ed. UFMG, 2012, pp. 47-69.

MOSER, Walter. As relações entre as artes: por uma arqueologia da Intermidialidade. Revista Aletria, v. 14, jul-dez, pp. 42-65, 2006.

PEREC, Georges. A coleção particular. Tradução de Ivo Barroso. São Paulo: Cosac Naify, 2004.

PINO, Claudia Amigo. A ficção da escrita. Cotia, SP: Ateliê Editorial, 2004.

SILVA, Natália Ubirajara; SANCHOTENE, Virgínia Crivellaro. A relação escritor-leitor nas obras do OuLiPo. Revista Palimpsesto, Rio de Janeiro, v. 20, n. 35, pp. 656-677, 2021.

SILVA, Zacarias Eduardo da. Interseções: pintura e literatura em Un Cabinet d'Amateur de Georges Perec. 2015. 129f. Dissertação (Mestrado em Letras) - Faculdade de Letras, Universidade Federal de Minas Gerais. Belo Horizonte, 2015. 
Recebido em: 30/05/2021

Aceito em: 05/08/2021 